1 ANALYTICAL SCIENCE

2 \& TECHNOLOGY

Vol. 25, No. 6, 395-401, 2012

http://dx.doi.org/10.5806/AST.2012.25.6.395

\title{
Development of the testing method for vinyl chloride monomer (VCM) in polyvinyl chloride(PVC) samples
}

\author{
Deok-Jun Kweon, Ki-In Choi ${ }^{\star}$, Hui-Jeong Eom, Jae-In Lee and Zel-Ho Choi
}

Test \& Standard Center, Korea Institute of Ceramic Engineering \& Technology, Korea (Received November 23, 2012; Revised December 6, 2012; Accepted December 6, 2012)

\section{PVC 제품에서의 염화비닐 단량체 정량분석 방법에 관한 연구}

\author{
권덕준 · 최기인` · 엄희정 · 이재인 · 최철호 \\ 한국세라믹기술원 시험표준센터
}

(2012. 11. 23. 접수, 2012. 12. 6. 수정, 2012. 12. 6. 승인)

\begin{abstract}
This study presents a method for the quantitative analysis of residual vinyl chloride monomer (VCM) in PVC products. In elution solvent, the extraction efficiency was similar by ethanol, THF, and acetone, but using n-hexane, it indicated relatively low extraction efficiency. Measuring VCM in the pulverized PVC samples, it showed reasonable results in both the direct injection method and headspace method with GC/MS. Regarding analysis of VCM in the intermediate sponge samples, five laboratories showed good results, and from the results, it was considered that VCM quantitative method in this study was reliable.

요 약: 본 연구에서는 PVC 제품에 잔류하는 염화비닐 단량체(VCM)에 대한 정량분석방법을 제시하였 다. 용출용매의 경우, 에탄올, THF, 아세톤에서 유사한 추출효율을 나타내었으나, 노말헥산을 이용한 경 우에는 상대적으로 낮은 추출효율을 보였다. 분쇄 PVC 시료에 VCM 표준용액을 주입한 분석시료에 대 한 $\mathrm{VCM}$ 함유량 측정 결과, $\mathrm{GC} / \mathrm{MS}$ 를 이용한 직접주입법이나 헤드스페이스법 모두 양호한 결과를 나타 내었다. $\mathrm{PVC}$ 제품의 중간물질인 스펀지에서의 $\mathrm{VCM}$ 분석과 관련하여 5 개 시험전문기관의 시험소간 비 교시험 결과, 각 시험소간 결과 편차가 크지 않은 것으로 나타나 본 연구에서 제시한 전처리 및 분석방 법에 대한 플라스틱 제품내의 $\mathrm{VCM}$ 정량방법이 유효한 것으로 판단되었다.
\end{abstract}

Key words: vinyl chloride monomer, polyvinyl chloride, plastics, test method

\section{1. 서 론}

플라스틱은 열·압력 등으로 소성변형시켜 성형할 수 있는 고분자물질이나 그 성형품, 천연수지 및 합성수
지의 총칭이지만 보통 플라스틱이라고 하면 합성수지 및 그 성형물을 가리킨다. 합성고분자물질은 고분자 화합물의 분자구조 및 열적 특성에 따라 열가소성 수 지와 열경화성 수지로 분류된다. 열가소성 수지라고도

Corresponding author

Phone : +82-(0)2-3282-7849 Fax : +82-(0)2-3282-2489

E-mail : kichoi@kicet.re.kr 
Table 1. Chemical characteristics of vinyl chloride monomer

\begin{tabular}{clllll}
\hline \hline Compound & \multicolumn{1}{c}{ Synonym } & CAS No. & Property & Use & Chemical structure \\
\hline $\begin{array}{c}\text { Vinyl chloride } \\
\text { monomer } \\
(\mathrm{VCM})\end{array}$ & $\begin{array}{l}\text { Vinyl chloride } \\
\text { Chloroethene }\end{array}$ & & Colorless & PVC base \\
Chloroethylene & $75-01-4$ & Gas & material & Sweet smell & \\
\hline
\end{tabular}

불리는 열가소성 플라스틱은 선상(線狀)구조 고분자 집합으로, 대표적인 플라스틱 종류라 할 수 있는데, 폴리염화비닐(poly vinyl chloride, PVC), 폴리스티렌 (polystyrene, PS), 폴리프로필렌(polypropylene, PP), 폴리 에틸렌(polyethylene, PE), 아크릴로니트릴-부타디엔-스 틸렌 수지(acrylonitrile butadiene styrene 수지) 등이 여기에 속한다. 열가소성 플라스틱은 가열하면 분자운 동이 활발해져서 고체인 중합체가 부드러워지고 점성 이 있는 액체가 되는데, 이 액체를 주형에 밀어 넣어 냉각, 성형하면 제품 형태의 수지가 된다. 이 종류의 플라스틱에서는 가열공정에 있어서 약간의 산화반응 이 열분해반응을 동반하는 경우가 있지만 본질적인 분자구조의 변화는 없다. 성형가공의 원리는 열경화성 수지와 다르고 가열시켜서 연화상태로 된 사이에 형 상을 성형하는 조작을 행한 후 즉시 냉각시켜서 고화 된 제품을 얻는 것이다. 그렇기 때문에 성형 사이클은 일반적으로 열경화성수지의 경우보다도 짧고 동일형 상의 성형품의 대량생산에 적용할 수 있고, 스크랩이 나 성형불량품을 재사용하는 것도 가능하다. 열가소성 수지는 분자 구조적으로 살펴보면 직쇄장고분자(약간 의 불순물을 포함 하고 있는 것도 있음)의 집합체이고, 이점에 있어서 가교구조를 보면 열경화성수지와 본질 적으로 다르게 되었고, 내용제성이나 열변형 온도 등 은 열경화성수지보다도 약하다. 그러나 적당한 방법에 의하면 쇄상분자를 가교구조에 따라서 내열성을 향상 시키는 것도 가능하다.

$\mathrm{PVC}, \mathrm{PS}, \mathrm{PP}, \mathrm{PE}$ 는 4대 플라스틱으로서 가장 많이 사용되고 있는 소재이며, 특히 $\mathrm{PVC}$ 는 가격이 저렴하 고 응용범위가 넓어 전세계적으로 년간 2,300 만톤 이 상 사용되는 $\mathrm{PE}$ 다음으로 많이 사용되고 있는 범용 플라스틱 소재이다. $\mathrm{PVC}$ 는 가소제, 안정제, 첨가제 등 과의 혼합성이 뛰어나 적은 양의 중합 첨가제의 변화 에도 다양한 성질의 플라스틱(경질 컨테이너부터 유 동성 필름까지)을 얻을 수 있기 때문에 플라스틱 중에 서도 다양성을 많이 가지는 플라스틱으로, 전선 피복, 각종 튜브, 전기기계제품, 호스, 포장 및 농업용 시트, 필름, 의류, 모조가죽, 각종 용기 및 생활용품, 2 차
원료 페이스트 등 건설, 자동차, 섬유, 농업 등 산업전 반에 걸쳐 폭넓게 사용되는 중요한 기초소재라 할 수 있다. 1935년의 전세계 PVC 소비량은 불과 1.1 만톤 정도이었지만, 1950년에는 22만톤, 1980년에는 1,100 만톤 그리고 1997년에는 약 2,300만톤으로 60년 동안 에 현저히 사용량이 증가하였다. 우리나라의 경우는 1966년 11월에 대한프라스틱에서 처음으로 PVC 수지 의 생산을 시작하였으며, 현재 우리나라의 전체 생산 능력은 년간 110 만톤 이상이다.

일반적으로 PVC는 클로로에 틸 렌(chloroethylene)으 로도 불리는 염화비닐 단량체(vinyl chloride monomer, $\mathrm{VCM}$ )를 중합하여 생산하는데, $\mathrm{VCM}$ 은 상온에서 감 미를 띤 취기를 갖는 상온에서는 기체로 존재하는 비 점 $-13.9{ }^{\circ} \mathrm{C}$ 의 무색의 물질이다. Table 1 에는 $\mathrm{VCM}$ 의 기본적인 특성을 나타내었다. ${ }^{1}$

$\mathrm{PVC}$ 중합과정에서 반응이 제대로 이루어지지 못할 경우, $\mathrm{PVC}$ 수지 내 $\mathrm{VCM}$ 이 미량 존재할 수 있는데, $\mathrm{VCM}$ 에 단기간 노출될 경우, 피부 및 눈 자극, 호흡곤 란, 불규칙한 심장박동, 두통, 지남력 상실, 관절 통증, 폐 울혈, 신경 이상 등을 유발하는 것으로 알려져 있 다. $\mathrm{VCM}$ 에 장기간 노출될 경우에는 발기불능, 푸른 빛 피부색, 혈액 장애, 간 이상, 암 등 각종 질병을 유 발하는 것으로 보고되고 있는데, 이에 미국산업안전보 건청(Occupational Safety and Health Administration, $\mathrm{OSHA}$ )에서는 $\mathrm{VCM}$ 을 발암성 물질로 구분하여 특별 관리하고, 국제 발암성연구소(International Agency for Research on Cancer, IARC) 및 미국국립독성계획단 (National Toxicology Program, NTP)에서는 인체 발암 성 확인물질인 $\mathrm{K}$ 및 그룹 1으로 분류하고 있다. 또한, 유럽연합(European Community, EC)에서도 VCM을 1 군 발암성 물질(R 45)로 분류하여 관리하고 있으며, 국내에서도 $\mathrm{VCM}$ 은 산업안전보건법에 따라 인체발암 성 확인물질(A1)으로 분류하여 허가대상유해물질, 작 업환경측정물질, 노출기준설정물질로 관리하고 있으 며, 유해화학물질관리법에서는 유독물 및 사고대비물 질로 관리하고 있다. 특히, 미국 FDA에서는 식품포장 에 사용되는 $\mathrm{PVC}$ 제품에 대하여 $10 \mathrm{ppb}$ 이하로 $\mathrm{VCM}$ 
Table 2. Standard methods for the determination of vinyl chloride monomer

\begin{tabular}{ll}
\hline \hline \multicolumn{1}{c}{ Method No. } & \multicolumn{1}{c}{ Title } \\
\hline KS K 0730 & Test method for residual vinyl chloride monomer(VCM) content of poly(vinyl chloride) fiber and resins \\
EPA 5021 & Volatile organic compounds in soils and other solid matrices using equilibrium headspace analysis \\
ISO 8762 & Workplace-Determination of vinyl chloride (charcoal tube/gas chromatographic method \\
ASTM D 3680 & Standard Test Method for Residual Vinyl Chloride Monomer Content of Poly(Vinyl Chloride) Resins, \\
(Withdrawn) & $\begin{array}{l}\text { Compounds, and Copolymers by Solution Injection Technique } \\
\text { ASTM D 3749 }\end{array}$ \\
& $\begin{array}{l}\text { Standard Test Method for Residual Vinyl Chloride Monomer in Poly(Vinyl Chloride) Resins by Gas Chro- } \\
\text { matographic Headspace Technique }\end{array}$ \\
\hline
\end{tabular}

을 규제하는 등 식품포장에 이용이 되는 $\mathrm{PVC}$ 중 $\mathrm{VCM}$ 농도 평가에 대한 관심이 증대되고 있다.

Table 2에는 VCM 분석방법에 대하여 규정하고 있 는 국내외 시험표준에 대하여 나타내었다. $\mathrm{VCM}$ 은 휘 발성이 크고 가스상으로 존재하기 때문에, 다른 유기 화합물에 비하여 시험이 어렵고, 시험방법에 따라 결 과의 재현성을 유지하기가 매우 어렵다. 현재 고분자 물질 중 $\mathrm{VCM}$ 을 분석하는 방법에 대해 규정하고 있 는 국내표준으로는 PVC를 테트라하이드로퓨란(THF) 에 넣고 $\mathrm{VCM}$ 을 용출하여 GC-flame ionization detector (FID)를 이용하여 분석하는 방법을 규정하는 $\mathrm{KS} \mathrm{K}$ 0730 이 있으나, KS K 0730의 제정 당시에 참조표준 으로 쓰인 ASTM D 3680은 2005년도에 폐지된 상태 로 현 $\mathrm{KS}$ 를 대체할 수 있는 보다 정확한 $\mathrm{VCM}$ 분석 방법 수립이 시급한 실정이다. 특히, 직접 $\mathrm{PVC}$ 를 $\mathrm{THF}$ 에 넣고 $\mathrm{VCM}$ 을 용출 분석할 경우(KS K 0730 방법), $\mathrm{PVC}$ 가 $\mathrm{THF}$ 에 용해되어 column을 통과할 때 $\mathrm{PVC}$ 중 일부가 column에 잔류하여 다음 시료 분석 결과에 영향을 줄 수 있으며, 분석기기도 FID보다는 $\mathrm{GC} / \mathrm{MS}$ 를 이용하거나 직접주입법(direct injection method)과 함께 고형시료 자체를 가열하여 휘발되는

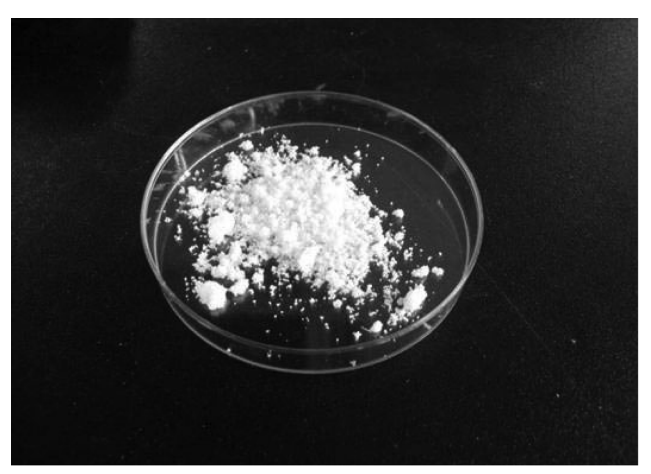

(a) PVC grinded sample
$\mathrm{VCM}$ 을 분석하는 방식인 헤드스페이스법(head-space method)을 고려하는 등 VCM 분석을 위한 다양한 분석 방법을 고려할 수 있다.

본 연구에서는 용매추출법을 사용하여 매질의 재질 에 상관없이 보편적으로 사용할 수 있는 최적의 추출 용매를 선택하는 한편, $\mathrm{GC} / \mathrm{MS}$ 를 이용하여 분석시료 직접주입법과 헤드스페이스법을 적용하는 과정에서의 분석조건을 확립함으로써 고분자 시료에 존재하는 $\mathrm{VCM}$ 분석방법을 확립하고자 하였다.

\section{2. 시험재료 및 분석방법}

\section{1. 시료의 조제}

$\mathrm{VCM}$ 분석조건 확립을 위하여 고분자 재료인 $\mathrm{PVC}$ 를 이용하여 분석조건 확립을 위한 시료를 조제하였 다. 시료 조제를 위한 PVC 시료는 한화케미칼에서 구 입한 PVC 수지를 사용하였으며, 사용에 앞서 냉동분 쇄하여 사용하였다. 시험용 시료는 $-20{ }^{\circ} \mathrm{C}$ 에서 $\mathrm{VCM}$ 표준원액(100 mg VCM/L)을 에탄올과 $1: 9$ 의 무게비 율로 희석하여 조제된 $\mathrm{VCM}$ 표준용액 $[1 \pm 0.01 \mathrm{mg}$ $\mathrm{VCM} / \mathrm{L}]$ 을 분취된 분쇄시료에 가하여 $\mathrm{GC} / \mathrm{MS}$ 분석조

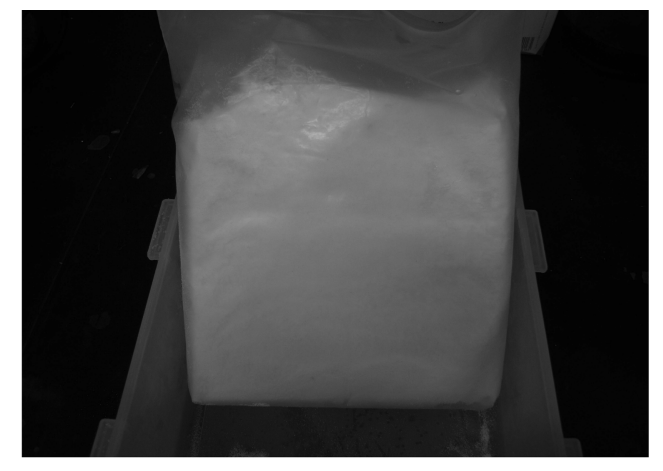

(b) PVC sponge

Fig. 1. PVC grinded sample and PVC sponge sample.

Vol. 25, No. 6, 2012 
건 확립을 위한 시험용 시료로 하였다. 한편, 시험소 간 비교시험에 사용된 실제 제품에서의 $\mathrm{VCM}$ 측정을 위한 분석용 시료는 VCM으로부터 PVC 파이프 등을 생산하는 과정의 중간 제품인 스펀지 형태의 제품을 구입하였다. 이 스펀지 시료는 반응하지 않은 $\mathrm{VCM}$ 이 존재하므로 기업에서는 $100{ }^{\circ} \mathrm{C}$ 정도에서 $\mathrm{VCM}$ 을 완 전히 제거하고 다음 공정으로 이동하여 사용하게 된 다. 본 실험실에서는 제거공정을 거치지 않은 스펀지 형태의 제품을 구입하여 "PVC 스펀지"라고 칭하고 $\mathrm{VCM}$ 분석용 시료로 하였다. 스펀지 시료는 적당한 크기로 잘라 $40{ }^{\circ} \mathrm{C}$ 건조기 내에서 얇게 펴서 시료의 에이징 과정을 거친 후, $\mathrm{VCM}$ 의 비등점인 $-14{ }^{\circ} \mathrm{C}$ 보 다 낮은 $-20{ }^{\circ} \mathrm{C}$ 의 냉장고에서 보관하여 $\mathrm{VCM}$ 의 추가 적인 기화를 방지하였다. Fig. 1에는 분석조건 확립 및 시험소간 비교실험을 위해 사용한 원 재료를 나타 내었다.

\subsection{VCM 용출용매의 선정 및 분석조건 확립}

$\mathrm{PVC}$ 수지에 함유된 $\mathrm{VCM}$ 을 용출하기에 적합한 용 매를 선정하기 위한 실험을 수행하였다. 사용된 용매 는 아세톤, $\mathrm{n}$-헥산, 에탄올 및 $\mathrm{THF}$ 등의 용매에 각각 vinyl chloride gas $10 \mathrm{~mL}$ 를 10 초에 걸쳐서 주사기로 주입 하여 밀봉한 다음 $-20{ }^{\circ} \mathrm{C}$ 의 온도에서 24 시간 정 도 보관하여 $\mathrm{VCM}$ 이 충분히 용해된 다음 분석하였다. $\mathrm{VCM}$ 의 전처리 및 분석조건 확립은 2.1 에 언급한 $\mathrm{PVC}$ 분쇄시료를 사용하여 $\mathrm{GC} / \mathrm{MS}$ 를 이용한 직접주 입법과 헤드스페이스법을 적용하였다. 직접주입법의 경우, 시험용 시료 약 $0.5 \mathrm{~g}$ 을 $0.1 \mathrm{mg}$ 까지 정확히 달 아 $20 \mathrm{~mL}$ 바이알에 넣고 선정된 추출용매 $10 \mathrm{~mL}$ 를 가한 다음 밀봉하여 $-20{ }^{\circ} \mathrm{C}$ 의 온도에서 24 시간 정도 보관하여 $\mathrm{VCM}$ 을 분석하였다. 헤드스페이스법의 경우, 시험용 시료 약 $0.5 \mathrm{~g}$ 을 $0.1 \mathrm{mg}$ 까지 정확히 달아 20 $\mathrm{mL}$ 헤드스페이스용 바이알에 넣고 선정된 추출용액 $10 \mathrm{~mL}$ 를 가한 다음 밀봉하고, 용액이 들어 있는 바이 알을 약 $90{ }^{\circ} \mathrm{C}$ 에서 약 1 시간 동안 교반한 다음 헤드스페이스 장치를 이용하여 분석하였다. $\mathrm{PVC}$ 스펀지 역시 직접주입법에 따라 $\mathrm{PVC}$ 분쇄시료와 동일한 방 법으로 시험소간 비교시험을 진행하였다.

정 량분석을 위해 사용한 $\mathrm{GC} / \mathrm{MS}$ 의 조건은 직접주 입법 및 헤드스페이스법 모두 VCM 화합물의 특성을 고려하여 전량 주입방식(splitless injection mode)을 적 용하였고 컬럼 내 헬륨가스 유속은 $1.3 \mathrm{~mL} / \mathrm{min}$ 이고, 초기 오븐온도 $30{ }^{\circ} \mathrm{C}$, initial time은 $5 \mathrm{~min}$. 그리고 $240{ }^{\circ} \mathrm{C}$ 까지 $20{ }^{\circ} \mathrm{C} / \mathrm{min}$ 으로 가열하였다. 질량분석기의
Table 3. Analytical conditions for the determination of VCM

\begin{tabular}{cll}
\hline \hline $\begin{array}{c}\text { Gas } \\
\text { chromatograph }\end{array}$ & \multicolumn{2}{c}{ Agilent 6890 series GC/MS } \\
\hline \multirow{2}{*}{ Column } & DB - $624(30 \mathrm{~m} \times 0.32 \mathrm{~mm} \mathrm{ID} \times 0.18 \mu \mathrm{m}$ \\
& \multicolumn{2}{c}{ film thickness $)$} \\
\hline & Carrier gas & Helium \\
& Column head pressure & $0.32 \mathrm{psi}$ \\
Instrument & Injection type & Splitless \\
Settings & Carrier gas flow & $1.3 \mathrm{~mL} / \mathrm{min}$ \\
& Injection temp. & $220^{\circ} \mathrm{C}$ \\
& Detector temp. & $280{ }^{\circ} \mathrm{C}$ \\
& Mode & $\mathrm{Constant}$ flow \\
\hline \multirow{2}{*}{ Temperature } & Initial rate & $5 \mathrm{~min}$ at $30{ }^{\circ} \mathrm{C}$ \\
Program & Hold time & $20^{\circ} \mathrm{C} / \mathrm{min}$ to $240^{\circ} \mathrm{C}$ \\
& Final temp. increasing & $240^{\circ} \mathrm{C}$ \\
& Post run time & $5 \mathrm{~min}$ at $240{ }^{\circ} \mathrm{C}$
\end{tabular}

Table 4. Retention time and selected molecular ion of VCM chromatogram

\begin{tabular}{lccc}
\hline \hline Compounds & $\begin{array}{c}\text { Retention time } \\
{[\mathrm{min} .]}\end{array}$ & $\begin{array}{c}\text { Monitoring ion } \\
{[\mathrm{m} / \mathrm{z}]}\end{array}$ & $\begin{array}{c}\text { Selected ion } \\
{[\mathrm{m} / \mathrm{z}]}\end{array}$ \\
\hline Vinyl chloride & 1.8 & 27,64 & 62 \\
\hline
\end{tabular}

경우 $\mathrm{EI} 70 \mathrm{eV}$, Interface temp. $300{ }^{\circ} \mathrm{C}$ 등의 조건으로 $\mathrm{GC} / \mathrm{MS}$ 의 조건을 확립하였다. 기기분석 조건은 Table 3 과 같이 설정하였으며, $\mathrm{VCM}$ 의 컬럼 내 체류시간 및 정 량이온의 질량은 Table 4에 나타내었다.

한편, 분석조건의 적절성 및 $\mathrm{VCM}$ 정량을 위하여 해당 분석조건을 적용하여 $\mathrm{VCM}$ 표준용액을 이용하 여 검정곡선을 작성하였다. $\mathrm{VCM}$ 표준 용액 $(100 \mu \mathrm{g} /$ $\mathrm{mL}$ )은 ethanol을 첨가하여 각각 $1,2,5,10$ 및 20 $\mu \mathrm{g} / \mathrm{mL}$ 농도로 묽혀 사용하였다. 검정곡선은 내부 표 준물질을 이용한 반응계수(response factor)를 이용하 여 작성하였으며, 그 직선성 $\left(\mathrm{y}=2289 \mathrm{x}-53991, \mathrm{r}^{2}=0.996\right)$ 으로 판단할 때, 비교적 양호한 분석결과가 얻어지고

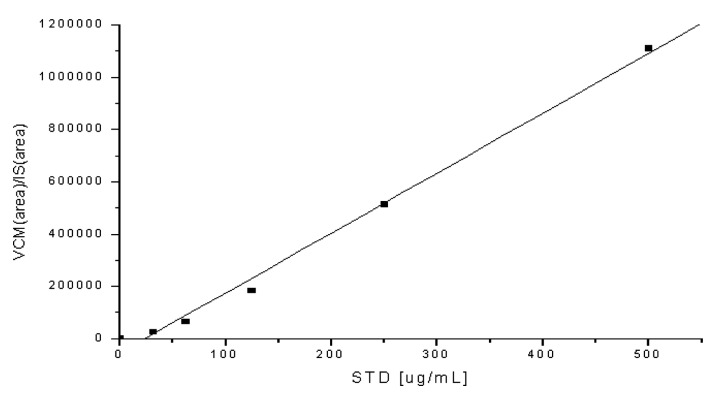

Fig. 2. Calibration curve for vinyl chloride standard solution. 
있음을 확인할 수 있었다. Fig. 2에는 $\mathrm{VCM}$ 정량에 사용된 검정곡선을 나타내었다.

\section{3. 결과 및 고찰}

\section{1. 용출 용매의 선정}

시료에 함유된 $\mathrm{VCM}$ 을 용출하기 위한 최적의 용매 를 선정하기 위한 실험을 수행하였다. Table 5에는 아 세톤, $\mathrm{n}$-헥산, 에탄올 및 $\mathrm{THF}$ 를 사용하였을 때의 용 매 내 $\mathrm{VCM}$ 잔류 농도를 $\mathrm{GC} / \mathrm{MS}$ (직접주입법)로 분석 한 결과를 나타내었다. 선택 용매 중에서는 에탄올을 용출 용매로 선택한 경우, $\mathrm{VCM}$ 의 농도가 $329.4 \mathrm{mg} /$ $\mathrm{L} 412.1 \mathrm{mg} / \mathrm{L}$ (평균 $370.4 \mathrm{mg} / \mathrm{L}$, 표준편차 $32.5 \mathrm{mg}$ / $\mathrm{L}$ )로 나타가 용출농도가 가장 높게 나타났으며, THF 를 사용한 경우에도 $\mathrm{VCM}$ 의 농도가 $305.3 \mathrm{mg} / \mathrm{L}$ $\sim 401.5 \mathrm{mg} / \mathrm{L}$ (평균 $352.8 \mathrm{mg} / \mathrm{L}$, 표준편차 $33.1 \mathrm{mg} / \mathrm{L}$ ) 로 상대적으로 높게 나타났다. 아세톤에서의 $\mathrm{VCM}$ 의 농도는 $302.5 \mathrm{mg} / \mathrm{L} 388.7 \mathrm{mg} / \mathrm{L}$ (평균 $338.9 \mathrm{mg} / \mathrm{L}$, 표 준편차 $23.9 \mathrm{mg} / \mathrm{L}$ )로 나타났다. 하지만, $\mathrm{n}$-헥산에서는 $\mathrm{VCM}$ 농도가 $219.3 \mathrm{mg} / \mathrm{L} 288.1 \mathrm{mg} / \mathrm{L}$ (평균 253.9 $\mathrm{mg} / \mathrm{L}$, 표준편차 $23.9 \mathrm{mg} / \mathrm{L}$ )로 나타나 용출 농도가 상 대적으로 낮게 나타났다. 아세톤, $\mathrm{n}$-헥산, 에탄올 및 $\mathrm{THF}$ 에 대한 각 분석차수에 대한 변동계수(표준편차/ 평균, coefficient of variation)는 각각 $0.07,0.09,0.09$, 0.09 로 나타나 용매별로 큰 차이를 보이지는 않았다. $\mathrm{VCM}$ 용출결과를 바탕으로 판단할 때, 시험에 사용할 용매는 에탄올, THF 및 아세톤 모두 선정가능할 것으 로 판단되었으나, 용매의 안정성 및 표준원액의 바탕 용매(에탄올)와의 혼합성 등을 고려하여 본 연구에서 는 에탄올을 용출용매로 선정하였다. 하지만, PVC가
$\mathrm{THF}$ 에 완전 용해되는 특성을 고려한다면 기타 PVC 재질의 수지에 대해서는 $\mathrm{THF}$ 를 이용하여 수지 내 $\mathrm{VCM}$ 을 용출하는 것도 가능한 것으로 판단된다.

\section{2. 분석 방법의 선정}

Table 6에는 VCM 표준용액을 첨가한 분쇄시료에 대한 직접분석법 및 헤드스페이스법에 따른 $\mathrm{GC} / \mathrm{MS}$ 분석결과를 나타내었다. 무작위로 채취한 PVC 분쇄 시료에 대한 분석결과는 두 시험방법 모두 약 $1 \mathrm{mg} /$ $\mathrm{kg}$ 수준의 $\mathrm{VCM}$ 이 검출된 것으로 나타나 $\mathrm{VCM}$ 에 대

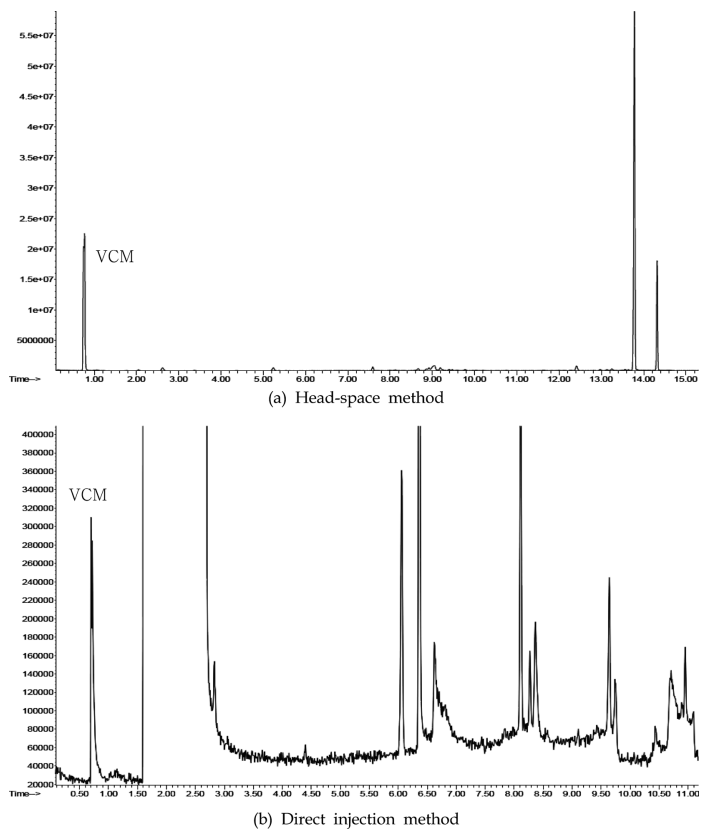

Fig. 3. GC/MS chromatogram of VCM.

Table 5. Leaching concentrations of VCM in various solvents

\begin{tabular}{|c|c|c|c|c|c|c|c|c|c|c|c|}
\hline \multirow{2}{*}{ Solvent } & \multicolumn{10}{|c|}{ VICM concentration (mg/L) } & \multirow{2}{*}{$\begin{array}{c}\text { Avg. } \\
(\mathrm{mg} / \mathrm{L})\end{array}$} \\
\hline & 1 & 2 & 3 & 4 & 5 & 6 & 7 & 8 & 9 & 10 & \\
\hline Acetone & 324.5 & 346.7 & 332.8 & 329.4 & 318.1 & 388.7 & 356.9 & 302.5 & 336.8 & 352.2 & 338.9 \\
\hline n-hexane & 252.4 & 288.1 & 219.3 & 282.6 & 220.7 & 272.8 & 263.3 & 251.4 & 233.6 & 255.1 & 253.9 \\
\hline $\mathrm{EhOH}$ & 386.7 & 392.0 & 345.6 & 329.4 & 402.2 & 412.1 & 329.9 & 333.0 & 396.4 & 376.2 & 370.4 \\
\hline THF & 305.3 & 321.4 & 381.2 & 365.8 & 392.4 & 354.2 & 345.2 & 312.5 & 348.2 & 401.5 & 352.8 \\
\hline
\end{tabular}

Table 6. Comparison of direct injection and head-space methods with GC/MS

\begin{tabular}{|c|c|c|c|c|c|c|c|c|c|c|c|}
\hline \multirow{2}{*}{$\begin{array}{l}\text { Injection } \\
\text { type }\end{array}$} & \multicolumn{10}{|c|}{ VCM concentration $(\mathrm{mg} / \mathrm{L})$} & \multirow{2}{*}{$\begin{array}{l}\text { Avg. } \\
(\mathrm{mg} / \mathrm{L})\end{array}$} \\
\hline & 1 & 2 & 3 & 4 & 5 & 6 & 7 & 8 & 9 & 10 & \\
\hline Direct injection & 1.23 & 1.42 & 0.98 & 0.87 & 0.84 & 1.45 & 1.37 & 1.21 & 1.15 & 0.99 & 1.15 \\
\hline Head-space method & 1.19 & 1.22 & 0.98 & 0.87 & 1.29 & 1.35 & 0.91 & 1.11 & 1.45 & 1.31 & 1.17 \\
\hline
\end{tabular}

Vol. 25, No. 6, 2012 
Table 7. VCM content in PVC sponge sample

\begin{tabular}{|c|c|c|c|c|c|c|c|c|c|c|c|}
\hline \multirow{2}{*}{ Sample } & \multicolumn{10}{|c|}{ VCM concentration $(\mathrm{mg} / \mathrm{kg})$} & \multirow{2}{*}{$\begin{array}{c}\text { Avg. } \\
(\mathrm{mg} / \mathrm{kg})\end{array}$} \\
\hline & 1 & 2 & 3 & 4 & 5 & 6 & 7 & 8 & 9 & 10 & \\
\hline PVC sponge & 7.5 & 8.1 & 8.3 & 7.9 & 7.1 & 8.9 & 8.5 & 7.6 & 7.4 & 8.7 & 8.0 \\
\hline
\end{tabular}

해서는 직접분석법 및 헤드스페이스법 모두 유효할 것으로 판단되었다. 하지만 Fig. 3에서 알 수 있듯이, 헤드스페이스법에 비해 직접분석법의 경우, 에탄올 피 크의 크기가 매우 $\mathrm{VCM}$ 피크 자체의 크기는 상대적 으로 낮게 나타났다. 이러한 피크의 상대적인 크기는 에탄올을 용매로 사용하는 VCM 분석에서 선택 이온 검출법(selected ion monitoring)이 적용할 경우, Table 6 에서 알 수 있듯이 정량에는 큰 영향을 미치지 못하 지만, 다양한 용매 주입에 따른 시료도입부 및 컬럼 내 주입 용매 부하, 시료 내 기타 방해물질의 영향에 따른 간섭현상, 질량검출기에 장착된 필라멘트 수명 등을 감안한다면 헤드스페이스법을 적용하여 $\mathrm{VCM}$ 을 분석하는 방법이 유리할 것으로 판단되었다.

\subsection{PVC 스펀지 시료를 이용한 재현성 시험}

Table 7에는 PVC 스펀지 시료에 대한 직접분석법 에 따른 $\mathrm{GC} / \mathrm{MS}$ 분석 결과를 나타내었다. 무작위로 10 회 채취한 $\mathrm{PVC}$ 스펀지 시료에 대한 $\mathrm{VCM}$ 측정농 도가 평균 $8.0 \mathrm{mg} / \mathrm{kg}(7.1 \sim 8.9 \mathrm{mg} / \mathrm{kg}$, 표준편차 0.6 $\mathrm{mg} / \mathrm{kg}$ )으로 나타났다. 이러한 측정 결과를 살펴볼 때, 휘발성이 큰 $\mathrm{VCM}$ 의 특성이나 사전 균질화 작업을 할 수 없었다는 점을 고려하더라도 재현성 있는 분석 결과를 얻은 것으로 판단되었다.

$\mathrm{PVC}$ 스편지 시료에 대한 $\mathrm{VCM}$ 함유량 평가를 위 한 전처리 및 분석에 대한 재현성을 평가하기 위하여 4 개 시험분석 전문기관에 추가적으로 $\mathrm{VCM}$ 분석을 의뢰하여 시험소간 비교시험을 진행하였다. 해당 시료 에 대한 전처리 및 분석 방법은 본 연구에서 적용한 방법과 동일하게 적용하였으며, $\mathrm{PVC}$ 스펀지 시료에 대한 시험소간 공동시험 결과는 Table 8에 나타내었다. 각 분석결과에 대한 표준편차는 0.8018 이고, 상대표준 편차가 $9.7315 \%$ 로서 나타나 시료의 보관이나 전처리 및 분석이 비교적 잘 이루어진 것으로 판단되었으며, Table 8과 Fig. 4에서 알 수 있듯이 z-score 역시 모든 시험소에서 2 이하로 나타나 PVC 스펀지 시료를 대 상으로 한 $\mathrm{VCM}$ 농도 정량방법에 대하여 각 시험소 간 반복성 및 재현성의 차가 양호하게 평가되어 본 연구에서의 $\mathrm{VCM}$ 전처리 및 정량방법은 유효한 것으
Table 8. Results of interlaboratory comparison test for determination of VCM in PVC sponge sample

\begin{tabular}{cccc}
\hline \hline Code & $\begin{array}{c}\text { VCM content } \\
(\mathrm{mg} / \mathrm{kg})\end{array}$ & $\begin{array}{c}\text { Deviation from } \\
\text { reference. } \\
\text { Value/\% }\end{array}$ & z-score \\
\hline Lab-1(A) & 7.6 & 5.0 & -0.49 \\
Lab-2(B) & 7.5 & 6.3 & -0.61 \\
Lab-3(C) & 8.7 & -8.7 & 0.86 \\
Lab-4(D) & 9.4 & -17.5 & 1.72 \\
Lab-5(E) & 8.0 & 0.0 & 0.00 \\
\hline
\end{tabular}

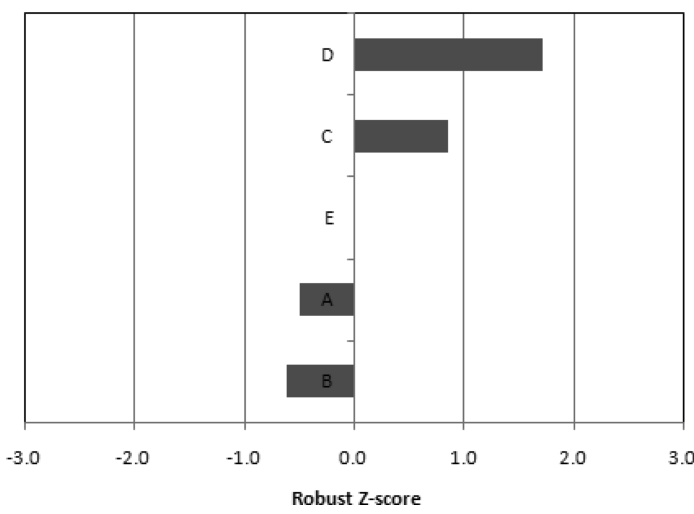

Fig. 4. Results of interlaboratory comparison test for determination of VCM in PVC sponge sample (z-score).

로 나타났다.

\section{4. 결 론}

플라스틱은 단량체의 화합적 결합(중합)반응을 통하 여 합성된 분자량이 수백에서 수십만인 거대 분자물 질로, 일상 생활용품, 자동차, 전기 - 전자, 정보통신, 디스플레이, 항공우주, 보건의료산업에 이르는 전 산 업분야에서 광범위하게 사용되는 핵심소재이다. 2000 년대 이후, 합성수지 및 1차 플라스틱 제품의 국내생 산은 지속적으로 증가하고 있으며(2009년 현재 20조 이상), 수출 역시 증가추세(2011년 현재 166억불 중국 이 약 $37 \%$ 를 차지)로 국내 주요 수출산업에서도 매우 중요한 비중을 차지하고 있다. ${ }^{7}$ 본 논문에서는 최근 
강화되고 있는 제품 내 국제환경규제 강화 추세에 대 응할 수 있도록 플라스틱 제품의 유해물질 중 하나인 $\mathrm{VCM}$ 에 대한 정량분석방법 수립을 위함으로써 무역 기술장벽에 능동적으로 대처하기 위한 기초적인 연구 를 다루었다. 용출용매의 경우, 에탄올, THF, 아세톤 에서 유사한 추출 효율을 나타내었다. 또한, 분쇄 $\mathrm{PVC}$ 시료에 $\mathrm{VCM}$ 표준용액을 주입하여 조제한 분석 시료에 대한 $\mathrm{VCM}$ 함유량 측정 방법을 확인한 결과, $\mathrm{GC} / \mathrm{MS}$ 를 이용한 직접주입법이나 헤드스페이스법 모 두 양호한 결과를 나타내었다. PVC 제품의 중간물질 인 스펀지에서의 $\mathrm{VCM}$ 분석과 관련하여 5 개 시험전 문기관의 시험소간 비교시험 결과, 각 시험소간 결과 편차가 크지 않은 것으로 나타나 본 연구에서 제시한 전처리 및 분석방법에 대한 플라스틱 제품내의 $\mathrm{VCM}$ 정량방법이 유효한 것으로 나타났다.

\section{참고문헌}

1. The Vinyl Institute; http://www.vinylinfo.org/aboutvi/ vi_commitment2.html

2. KS K 0730, Test method for residual vinyl chloride
monomer(VCM) content of poly(vinyl chloride) fiber and resins, Korean Agency for Technologys and Standards, 2009.

3. EPA method 5021, Volatile organic compounds in soils and other solid matrices using equilibrium headspace analysis, US Environmental Protection Agency, 1996.

4. ISO 8762, Workplace-Determination of vinyl chloride charcoal tube/gas chromatographic method, International Organization for Standardization, 1988.

5. ASTM D 3680, Standard Test Method for Residual Vinyl Chloride Monomer Content of Poly(Vinyl Chloride) Resins, Compounds, and Copolymers by Solution Injection Technique, American Society for Testing and Materials, 2005.

6. ASTM D 3749, Standard Test Method for Residual Vinyl Chloride Monomer in Poly(Vinyl Chloride) Resins by Gas Chromatographic Headspace Technique, American Society for Testing and Materials, 2008.

7. Ministry of Knowledge Economy, http://www.mctnet. org/index.jsp 